\title{
Chemical and Structural Variety in Sodium Thioarsenate Glasses Studied by Neutron Diffraction and Supported by First-Principles Simulations
}

Mohammad Kassem, ${ }^{1}$ Tinehinane Bounazef, ${ }^{1}$ Daniele Fontanari, ${ }^{1}$ Anton Sokolov, ${ }^{1}$ Maria Bokova, ${ }^{1}$ Alex C. Hannon, ${ }^{2}$ and Eugene Bychkov*,1

${ }^{1}$ Laboratoire de Physico-Chimie de l'Atmosphère, Université du Littoral Côte d’Opale, 59140 Dunkerque, France

2 ISIS Facility, Rutherford Appleton Laboratory, Chilton, Didcot, OX11 0QX, U.K.

\section{SUPPORTING INFORMATION}

Figure S1. Characteristic structural motifs in (1) monoclinic $\mathrm{As}_{2} \mathrm{~S}_{3}$, (2) monoclinic $\mathrm{NaAsS}_{2}$, (3) cubic $\mathrm{Na}_{3} \mathrm{AsS}_{3}$, and (4) face-centered cubic $\mathrm{Na}_{2} \mathrm{~S}$.

Figure S2. Some pictures of preliminary synthesized materials in the $\mathrm{Na}_{2} \mathrm{~S}-\mathrm{As}_{2} \mathrm{~S}_{3}$ system using vitreous carbon crucibles in evacuated silica tubes.

Figure S3. Composition dependences of (a) principle peak (PP) and (b) second principle peak (PP2) positions, and (c) PP and PP2 amplitudes in sodium thioarsenate glasses $\left(\mathrm{Na}_{2} \mathrm{~S}\right)_{x}\left(\mathrm{As}_{2} \mathrm{~S}_{3}\right)_{1-x}$.

Figure S4. Glass transition temperatures $T_{\mathrm{g}}$ in sodium thioarsenate glasses $\left(\mathrm{Na}_{2} \mathrm{~S}\right)_{x}\left(\mathrm{As}_{2} \mathrm{~S}_{3}\right)_{1-\mathrm{x}}$.

Figure S5. Typical Raman spectra of $\left(\mathrm{Na}_{2} \mathrm{~S}\right)_{x}\left(\mathrm{As}_{2} \mathrm{~S}_{3}\right)_{1-x}$ glasses revealing the presence of As-As and S-S stretching at $\approx 230$ and $470-490 \mathrm{~cm}^{-1}$, respectively.

Figure S6. Experimental neutron pair-distribution function $g_{\mathrm{N}}(r)$ for glassy $\left(\mathrm{Na}_{2} \mathrm{~S}\right)_{0.3}\left(\mathrm{As}_{2} \mathrm{~S}_{3}\right)_{0.7}$ (blue) and its FPMD replica (magenta) obtained using the GGA/PBEsol functional.

Figure S7. FPMD partial structure factors $S_{i j}(Q)$ for glassy $\left(\mathrm{Na}_{2} \mathrm{~S}\right)_{0.3}\left(\mathrm{As}_{2} \mathrm{~S}_{3}\right)_{0.7}$ obtained using hybrid GGA/PBE0 exchange-correlation functional.

Figure S8. Preferential conduction pathways in glassy silver thiogermanates, and ${ }^{110 \mathrm{~m}} \mathrm{Ag}$ tracer diffusion in high- and low-temperature $\mathrm{Ag}_{2} \mathrm{~S}$ crystalline polymorphs, and silver sulfide glasses.

Figure S9. Conductivity temperature dependences for glassy $\left(\mathrm{Na}_{2} \mathrm{~S}\right)_{0.3}\left(\mathrm{As}_{2} \mathrm{~S}_{3}\right)_{0.7}$ (blue circles and triangles) and $\left(\mathrm{Na}_{2} \mathrm{~S}\right)_{0.33}\left(\mathrm{GeS}_{2}\right)_{0.67}$ (red line).

Figure S10. $\mathrm{As}_{p} \mathrm{~S}_{q}$ ring statistics in (a) glassy $\mathrm{As}_{2} \mathrm{~S}_{3}$ and (b) monoclinic orpiment or triclinic anorpiment.

Figure S11. Experimental and DFT Raman spectra of sodium thioarsenate glasses.

*corresponding author; email: bychkov@univ-littoral.fr 

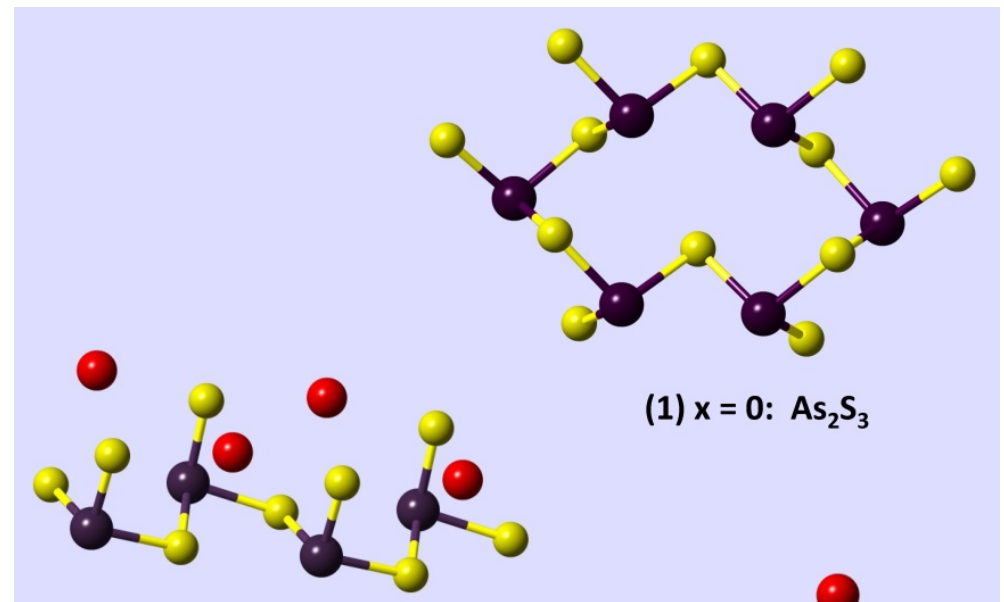

(1) $\mathrm{x}=0: \mathrm{As}_{2} \mathrm{~S}_{3}$

(2) $\mathrm{x}=0.50: \mathrm{NaAsS}_{2}$

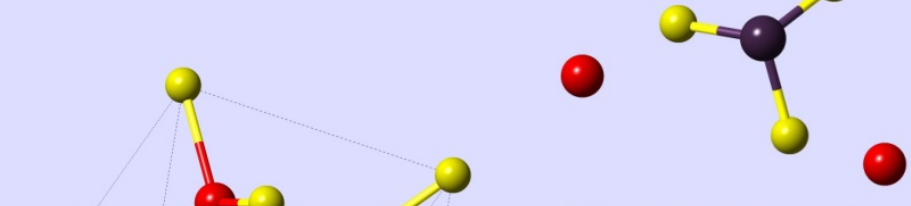

(3) $\mathrm{x}=0.75: \mathrm{Na}_{3} \mathrm{AsS}_{3}$

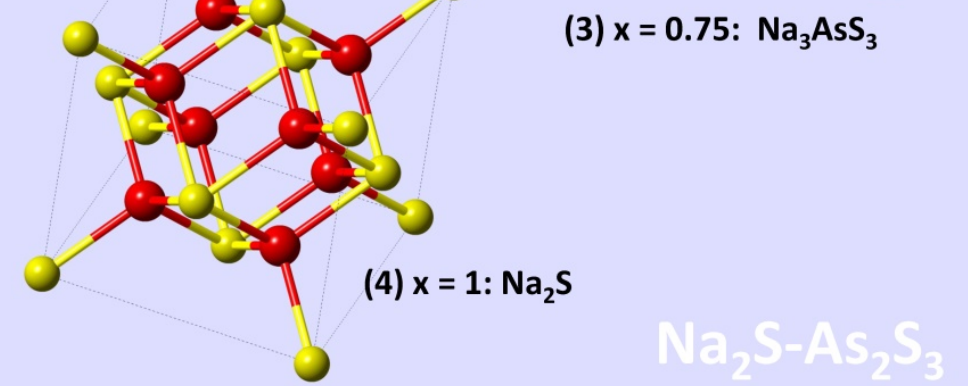

Figure S1. Characteristic structural motifs in (1) monoclinic $\mathrm{As}_{2} \mathrm{~S}_{3},{ }^{, 1}$ (2) monoclinic $\mathrm{NaAsS}_{2},{ }^{\mathrm{s2}}$ (3) cubic $\mathrm{Na}_{3} \mathrm{AsS}_{3},{ }^{\mathrm{s}}$ and (4) face-centered cubic $\mathrm{Na}_{2} \mathrm{~S}^{.54}$ 


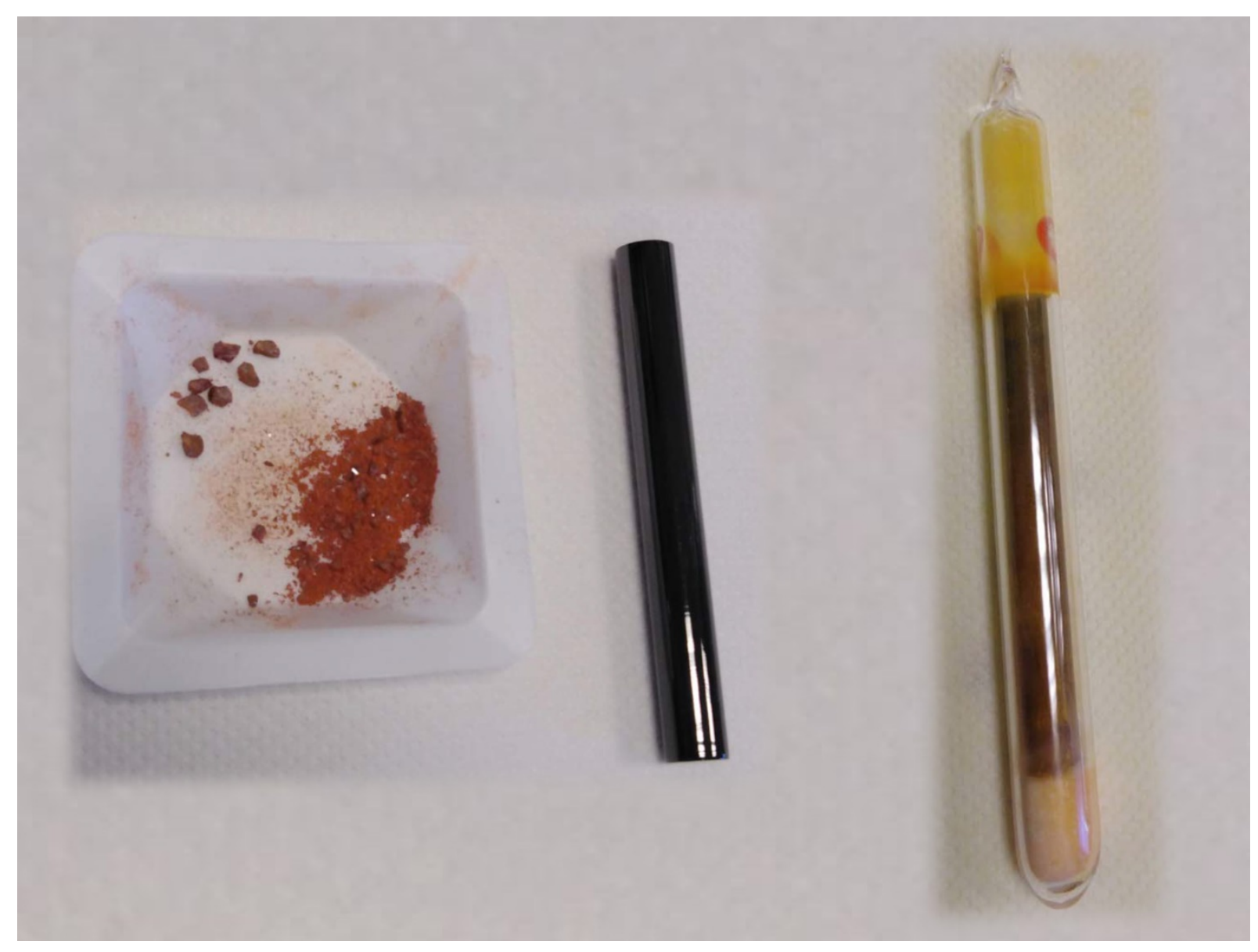

Figure S2. Some pictures of preliminary synthesized materials in the $\mathrm{Na}_{2} \mathrm{~S}-\mathrm{As}_{2} \mathrm{~S}_{3}$ system using vitreous carbon crucibles in evacuated silica tubes. 

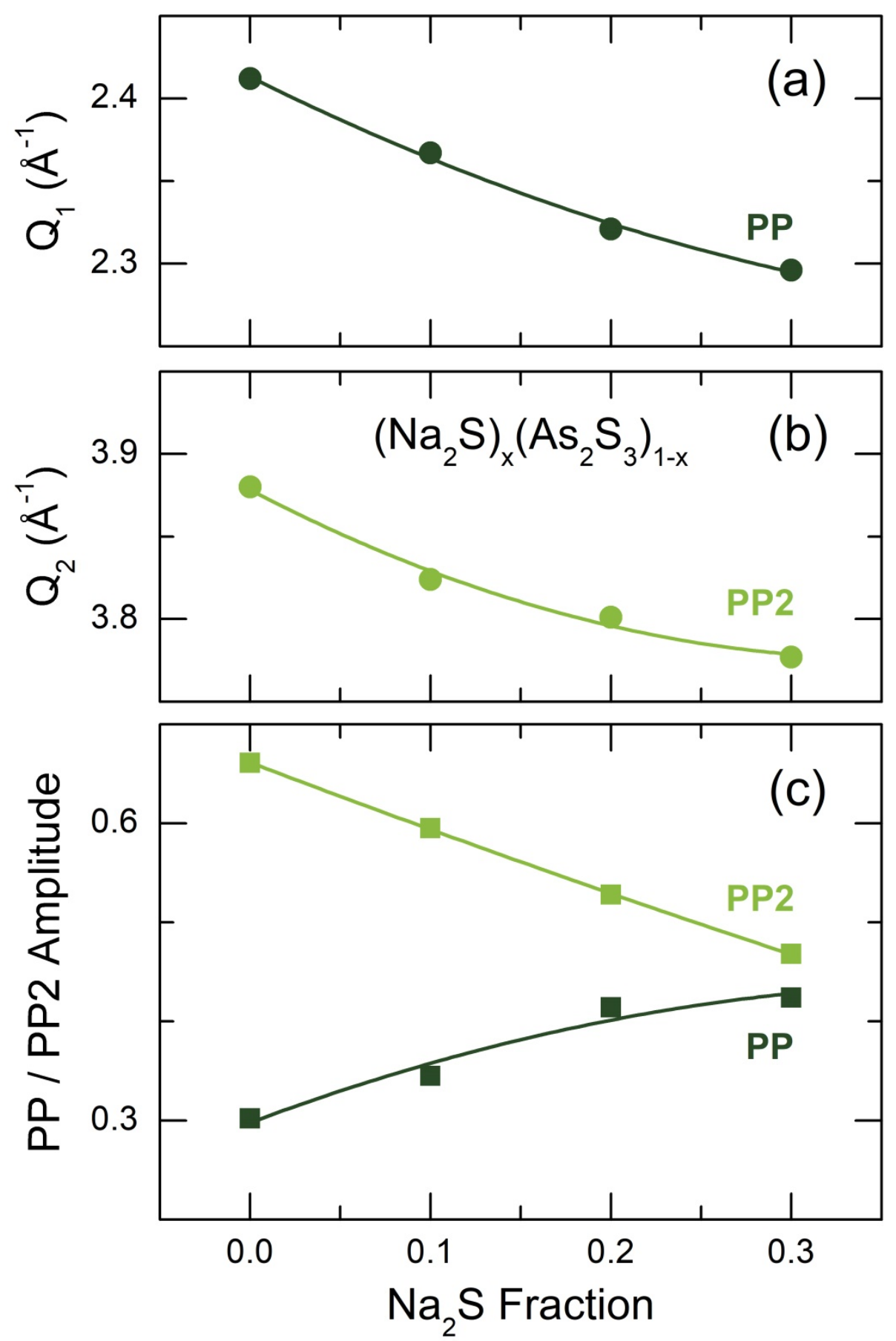

Figure S3. Composition dependences of (a) the principle peak (PP) and (b) the second principle peak (PP2) positions, and (c) the PP and PP2 amplitudes in sodium thioarsenate glasses $\left(\mathrm{Na}_{2} \mathrm{~S}\right)_{x}\left(\mathrm{As}_{2} \mathrm{~S}_{3}\right)_{1-x}$. 


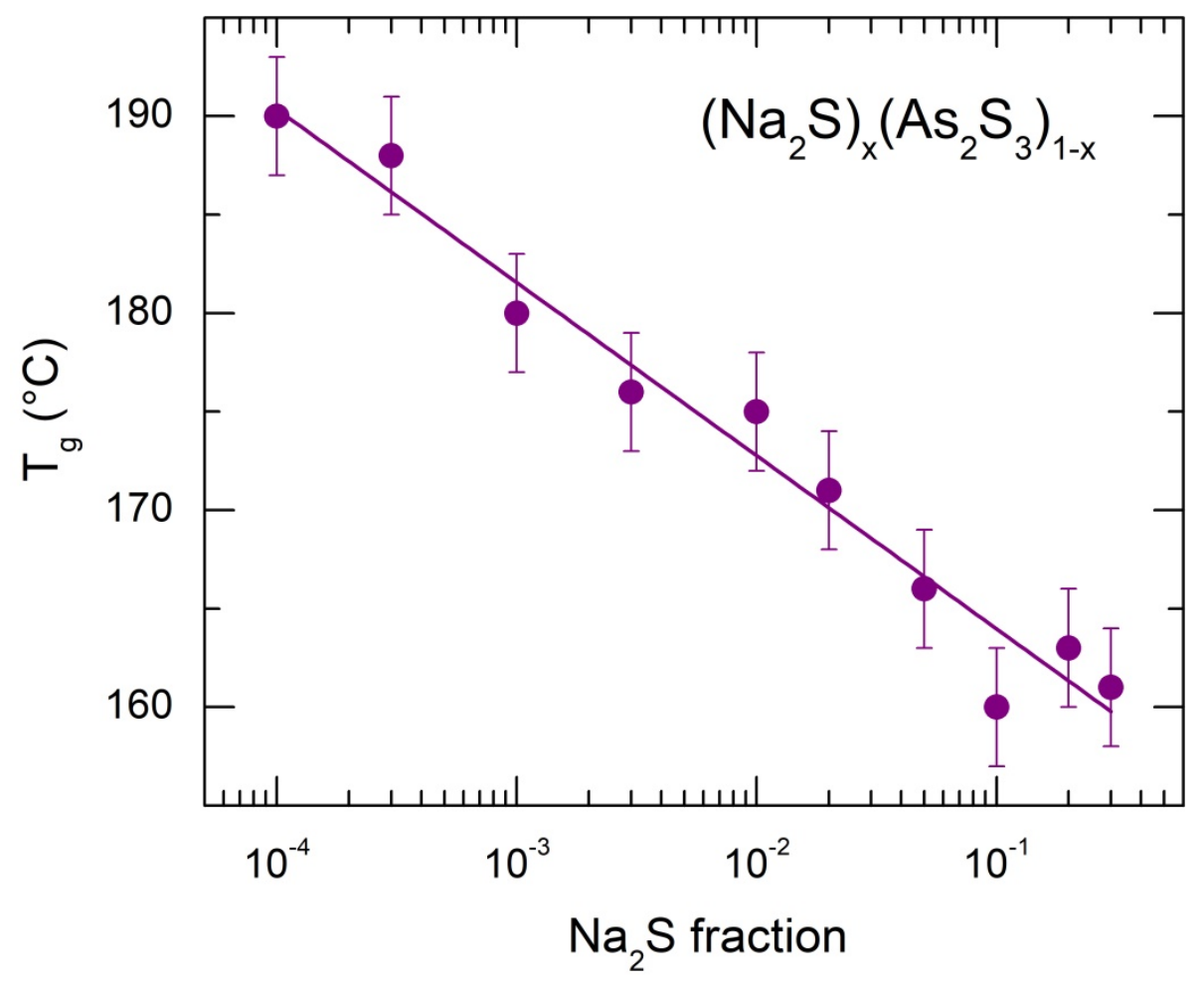

Figure S4. Glass transition temperatures $T_{\mathrm{g}}$ in sodium thioarsenate glasses $\left(\mathrm{Na}_{2} \mathrm{~S}\right)_{x}\left(\mathrm{As}_{2} \mathrm{~S}_{3}\right)_{1-x}$ as a function of $x$. 


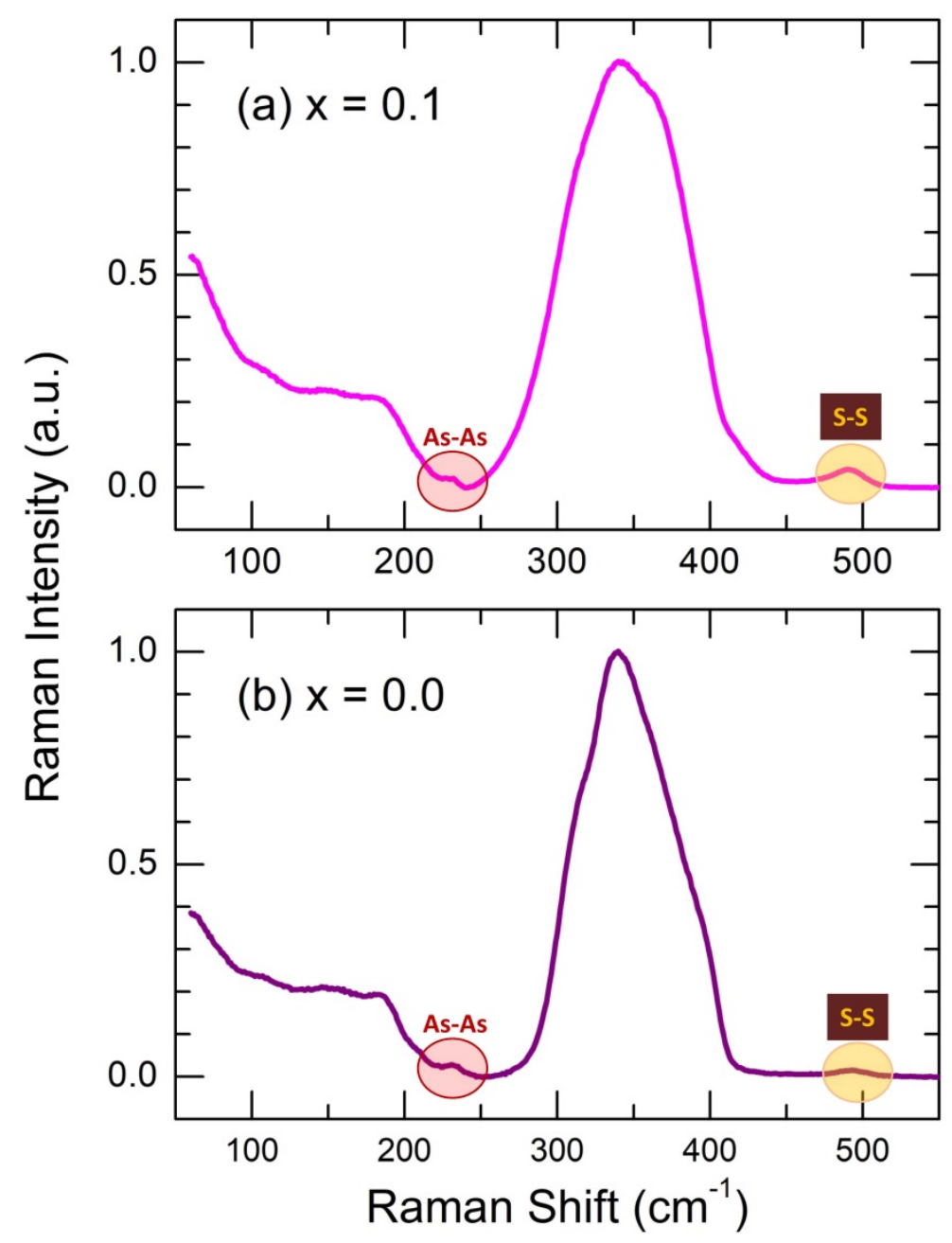

Figure S5. Typical Raman spectra of $\left(\mathrm{Na}_{2} \mathrm{~S}\right)_{x}\left(\mathrm{As}_{2} \mathrm{~S}_{3}\right)_{1-x}$ glasses revealing the presence of As-As and S-S stretching at $\approx 230$ and $470-490 \mathrm{~cm}^{-1}$, respectively; (a) $x=0.1$, (b) $x=0.0$. 


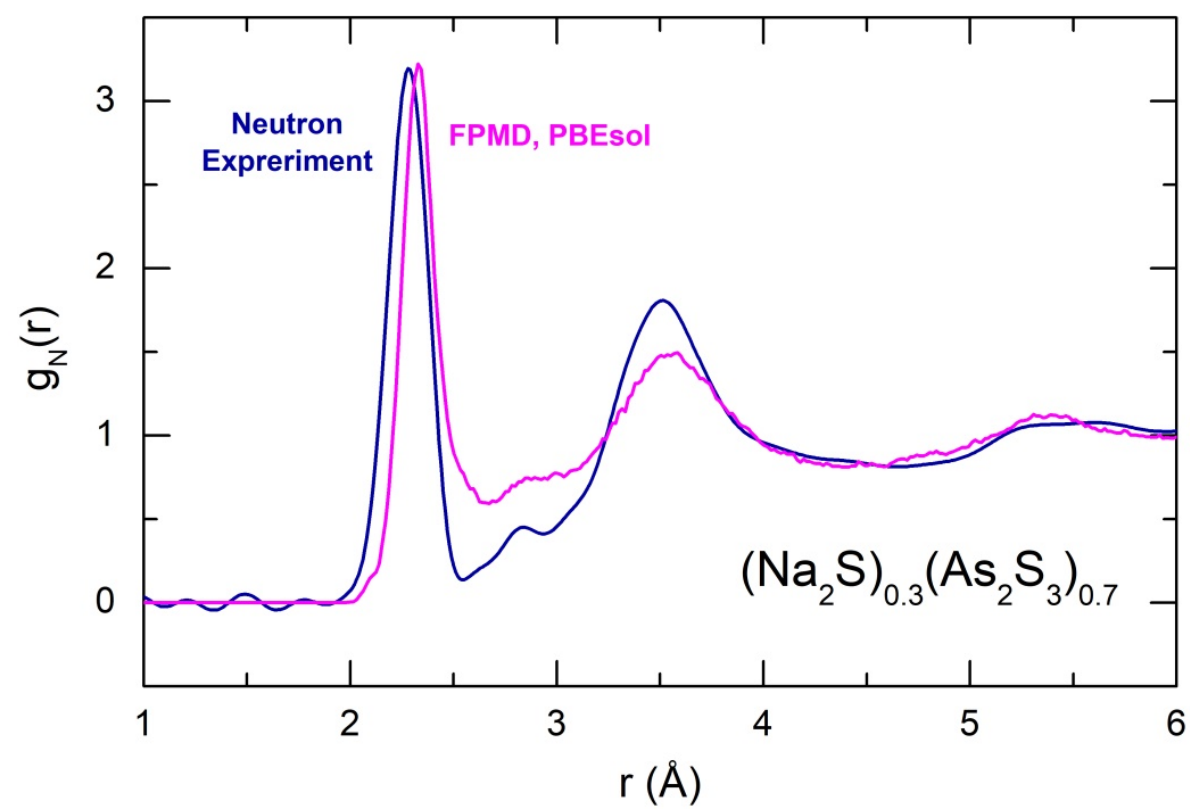

Figure S6. Experimental neutron pair-distribution function $g_{\mathrm{N}}(r)$ for glassy $\left(\mathrm{Na}_{2} \mathrm{~S}\right)_{0.3}\left(\mathrm{As}_{2} \mathrm{~S}_{3}\right)_{0.7}$ (blue) and its FPMD replica (magenta) obtained using the GGA/PBEsol functional. 


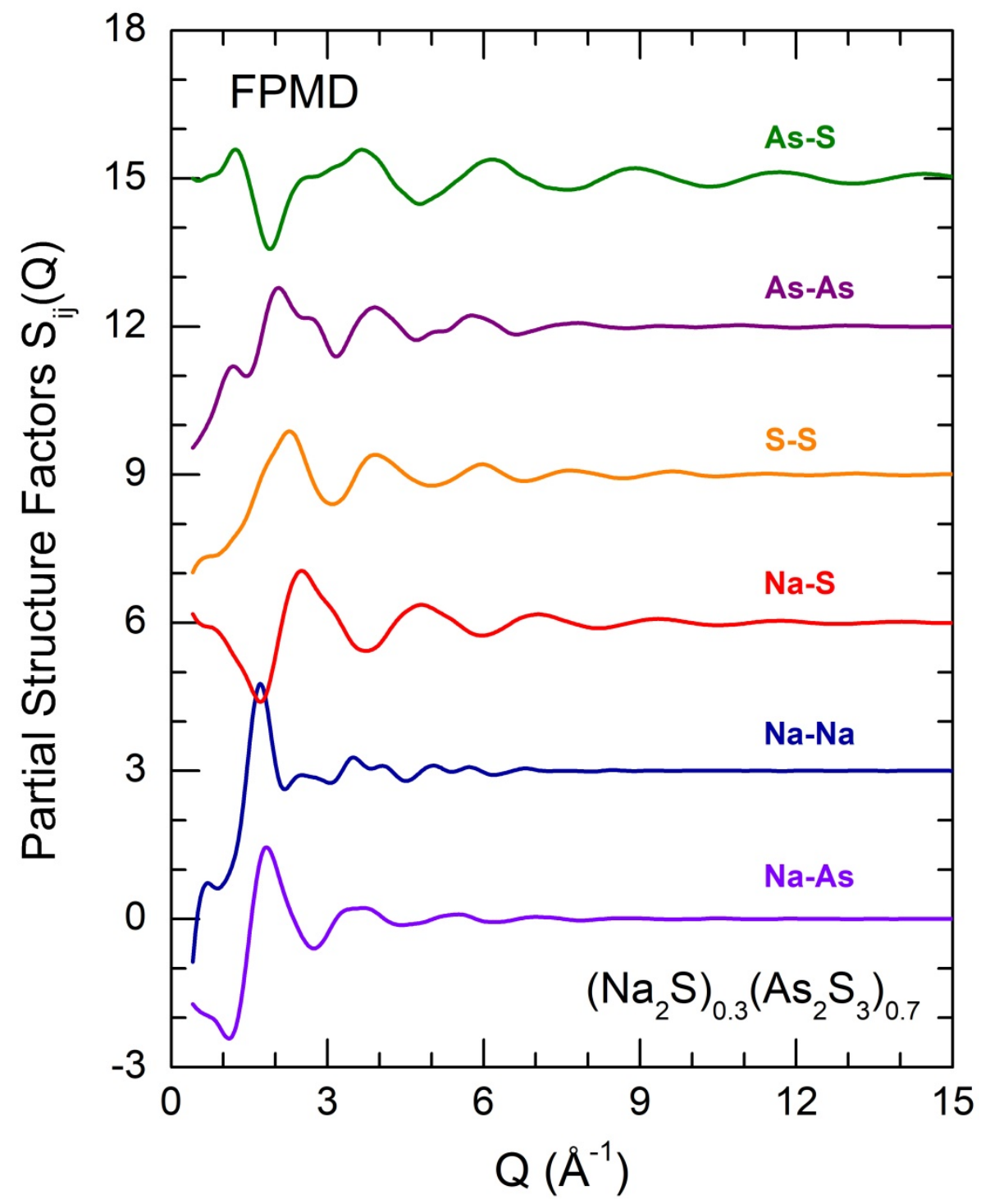

Figure S7. FPMD partial structure factors $S_{i j}(Q)$ for glassy $\left(\mathrm{Na}_{2} \mathrm{~S}\right)_{0.3}\left(\mathrm{As}_{2} \mathrm{~S}_{3}\right)_{0.7}$ obtained using hybrid GGA/PBE0 exchange-correlation functional. 

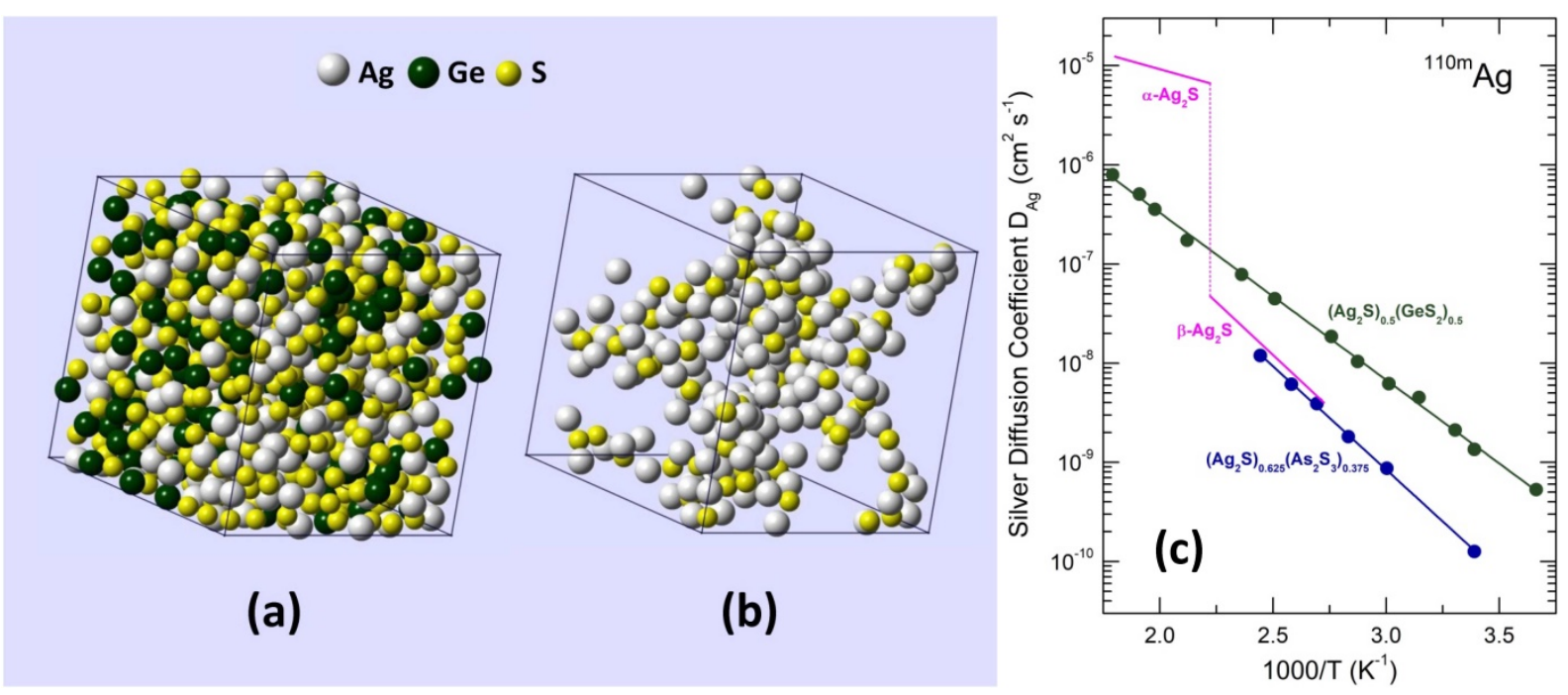

Figure S8. Preferential conduction pathways in glassy silver thiogermanates,,$^{55}$ and ${ }^{110 \mathrm{~m}} \mathrm{Ag}$ tracer diffusion in high- and low-temperature $\mathrm{Ag}_{2} \mathrm{~S}$ crystalline polymorphs, and silver sulfide glasses. FPMD simulation box for glassy $\left(\mathrm{Ag}_{2} \mathrm{~S}\right)_{0.45}\left(\mathrm{GeS}_{2}\right)_{0.55}$ : (a) the entire box, (b) the isolated sulfur species $S_{\text {iso }}$ with connected $\mathrm{Ag}$ cations, $\mathrm{Ag} / \mathrm{S}_{\text {iso }}=2.1 \pm 0.1$; (c) silver tracer diffusion coefficients in $\alpha$ - and $\beta-\mathrm{Ag}_{2} \mathrm{~S}$,, 6 and silver thioarsenate and thiogermanate glasses. .5 


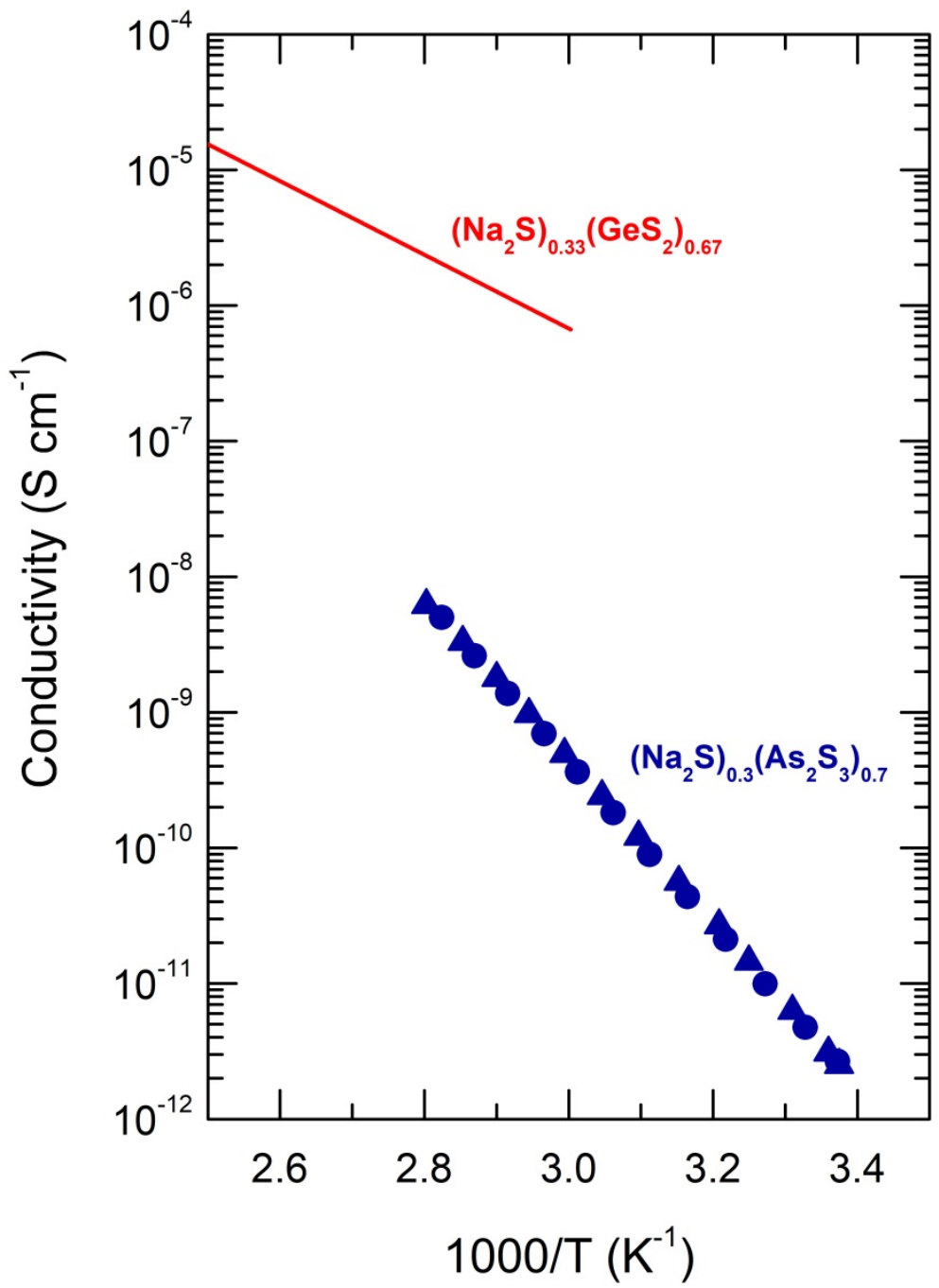

Figure S9. Conductivity temperature dependences for glassy $\left(\mathrm{Na}_{2} \mathrm{~S}\right)_{0.3}\left(\mathrm{As}_{2} \mathrm{~S}_{3}\right)_{0.7}$ (blue circles and triangles) and $\left(\mathrm{Na}_{2} \mathrm{~S}\right)_{0.33}\left(\mathrm{GeS}_{2}\right)_{0.67}$ (red line). ${ }^{\mathrm{S}, 58}$ 


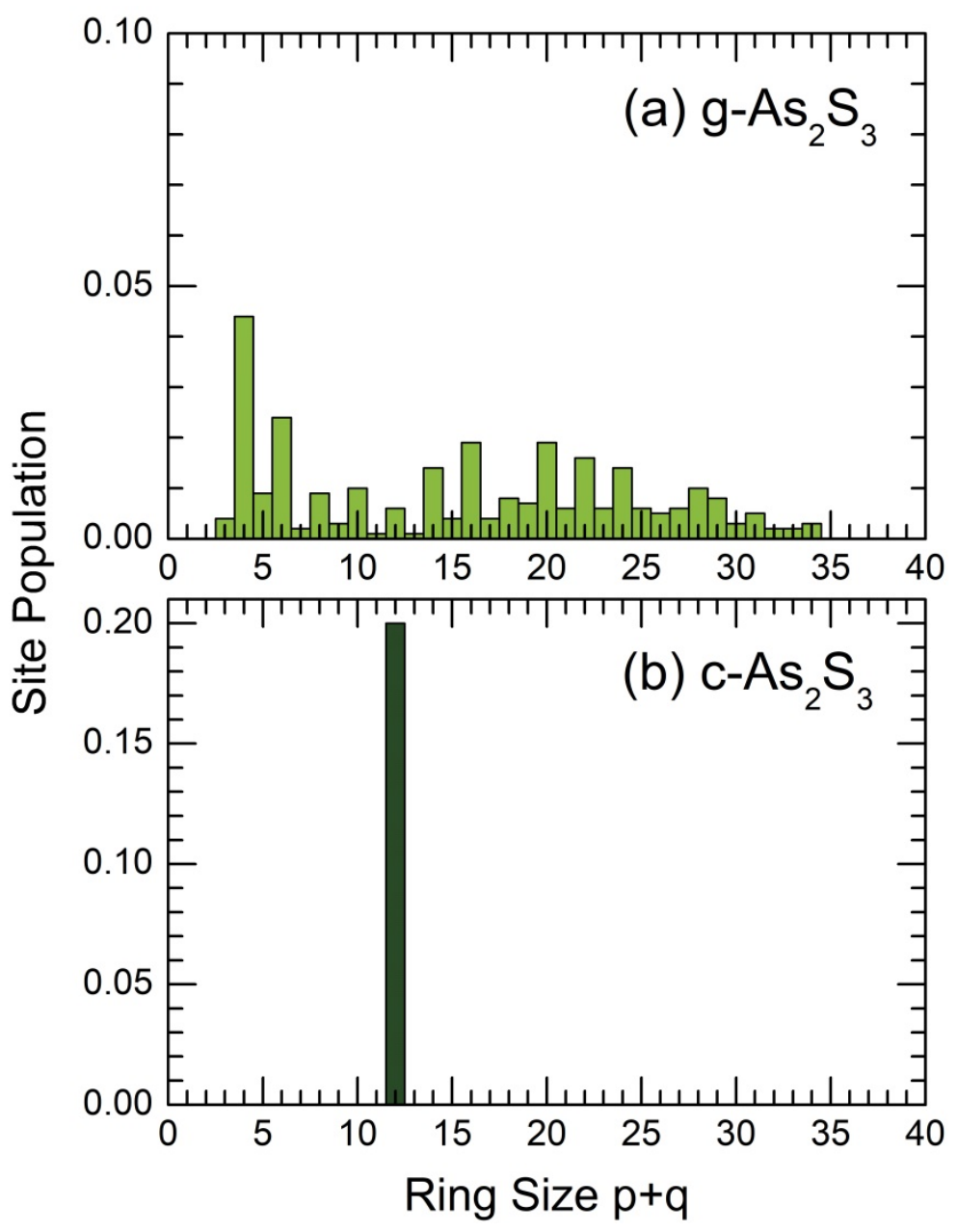

Figure S10. $\mathrm{As}_{p} \mathrm{~S}_{q}$ ring statistics in (a) glassy $\mathrm{As}_{2} \mathrm{~S}_{3}$ and (b) monoclinic orpiment or triclinic anorpiment. 


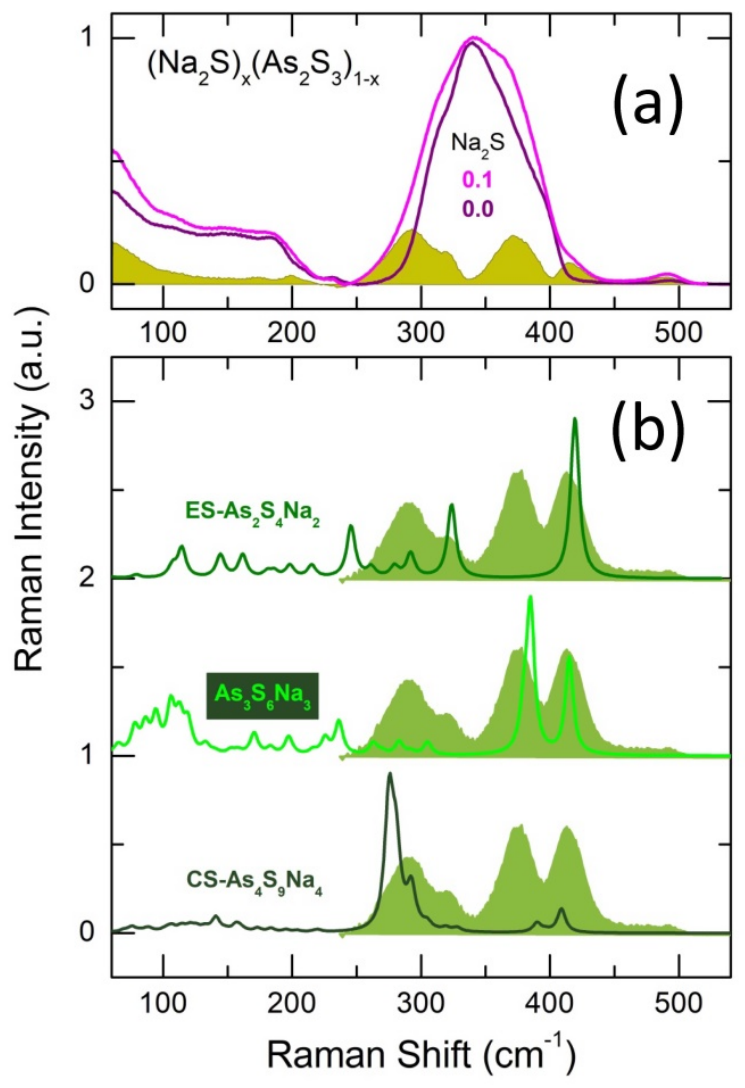

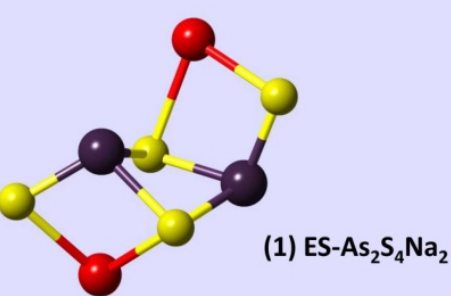

(c)

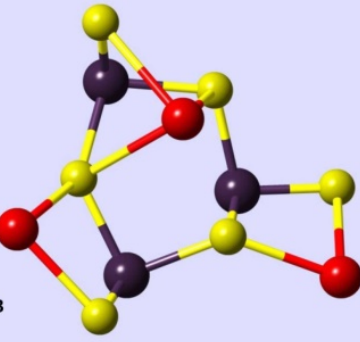

(2) $\mathrm{As}_{3} \mathrm{~S}_{6} \mathrm{Na}_{3}$

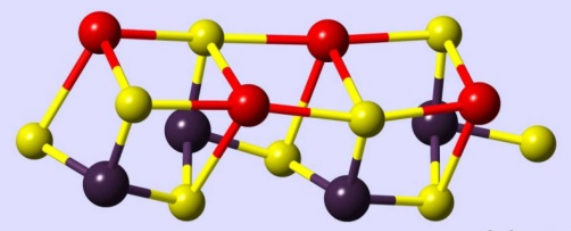

(3) $\mathrm{CS}-\mathrm{As}_{4} \mathrm{~S}_{9} \mathrm{Na}_{4}$

Figure S11. Experimental and DFT Raman spectra of sodium thioarsenate glasses: (a) typical subtraction procedure to derive a difference spectrum, related to sodium species, using the normalized Raman spectrum for $\left(\mathrm{Na}_{2} \mathrm{~S}\right)_{0.1}\left(\mathrm{As}_{2} \mathrm{~S}_{3}\right)_{0.9}$ and properly scaled g-As ${ }_{2} \mathrm{~S}_{3}$ spectral envelope; (b) DFT Raman spectra for (1) $\mathrm{ES}-\mathrm{As}_{2} \mathrm{~S}_{4} \mathrm{Na}_{2}$, (2) $\mathrm{As}_{3} \mathrm{~S}_{6} \mathrm{Na}_{3}$, and (3) $\mathrm{CS}-\mathrm{As}_{4} \mathrm{~S}_{9} \mathrm{Na}_{4}$ clusters in comparison with the difference spectrum for $\left(\mathrm{Na}_{2} \mathrm{~S}\right)_{0.35}\left(\mathrm{As}_{2} \mathrm{~S}_{3}\right)_{0.65}$, highlighted in light green; (c) the DFT-optimized (1) $\mathrm{ES}_{-} \mathrm{As}_{2} \mathrm{~S}_{4} \mathrm{Na}_{2}$, (2) $\mathrm{As}_{3} \mathrm{~S}_{6} \mathrm{Na}_{3}$, and (3) $\mathrm{CS}-\mathrm{As}_{4} \mathrm{~S}_{9} \mathrm{Na}_{4}$ clusters used for harmonic frequency calculations. 


\section{References}

(s1) Mullen, D. J. E.; Nowacki, W. Refinement of the Crystal Structures of Realgar AsS and Orpiment, $\mathrm{As}_{2} \mathrm{~S}_{3}$. Z. Kristallogr. 1972, 136, 48-65.

(s2) Iglesias, J. E.; Zuniga, F. J.; Nowacki, W. $\mathrm{NaAsS}_{2}$, a Synthetic Sulfosalt Related to the NaCl Type. Z. Kristallogr. 1977, 146, 43-52.

(s3) Palazzi, M. Structure Cristalline de l'Orthotrithioarsenite Trisodique, $\mathrm{Na}_{3} \mathrm{AsS}_{3}$. Acta Crystal. B 1976, 32, 3175-3177.

(s4) Bonneau, P. R.; Jarvis, R. F. jr.; Kaner, R. B. Solid-State Metathesis as a Quick Route to TransitionMetal Mixed Dichalcogenides. Inorg. Chem. 1992, 31, 2127-2132.

(s5) Alekseev, I.; Fontanari, D.; Sokolov, A., Bokova, M., Kassem, M.; Bychkov, E. Ionic Conductivity and Tracer Diffusion in Glassy Chalcogenides. In World Scientific Reference of Amorphous Materials, Vol. 1, Chapter 8; Taylor, P. C., ed.; World Scientific: Singapore, 2020; pp. 203-249.

(s6) Allen, R. L., Moore, W. J. Diffusion of Silver in Silver Sulfide. J. Phys. Chem. 1959, 63, 223-226.

(s7) Barrau, B.; Ribes, M.; Maurin, M.; Kone, A.; Souquet, J.-L. Glass Formation, Structure and Ionic Conduction in the $\mathrm{Na}_{2} \mathrm{~S}-\mathrm{GeS}_{2}$ System. J. Non-Cryst. Solids 1980, 37, 1-14.

(s8) Pradel, A.; Ribes M. Ionic Conductivity of Chalcogenide Glasses. In Chalcogenide Glasses: Preparation, Properties and Applications; Adam, J.-L., Zhang, X., Eds.; Woodhead Publ.: Oxford, 2014; pp 169-208. 